\title{
Management of Air Emphysema with Cyanosis Following Dental Treatment - A Case Report with Scientific Reasoning
}

\author{
Nafeesa Tabassum $^{1}$, Fatema Akhter², Ghada Alfirm³ ${ }^{3}$ Yara Alhumaidan ${ }^{4}$, Tahsinul Haque 5
}

1, 2 Department of Surgical and Diagnostic Sciences, College of Dentistry, Dar Al Uloom University, Riyadh, Kingdom of Saudi Arabia. ${ }^{3,4}$ College of Dentistry, Dar Al Uloom University, Riyadh, Kingdom of Saudi Arabia. ${ }^{5}$ Department of Oral Medicine and Diagnostic Sciences, College of Dentistry, King Saud University, Riyadh, Kingdom of Saudi Arabia.

\section{INTRODUCTION}

Air emphysema as a consequence of dental procedures is a rare but dangerous state if not diagnosed and treated timely. It can occur incidentally or iatrogenically in many dental procedures such as restorations, endodontic and periodontal treatments, surgical and non-surgical tooth extraction, and use of air or water sprays and syringes.1-6 Subcutaneous emphysema of dental origin most commonly occurs after surgical extraction of an impacted mandibular third molar. ${ }^{7}$ Several studies have reported that the use of high speed hand-piece during surgical extraction led to escape of air into the subcutaneous tissues.7-10 Wilson (1983) reported subcutaneous emphysema in the eyelids after extraction of the maxillary molar teeth due to vigorous irrigation combined with air and water spray for 10 seconds. ${ }^{6}$ Subcutaneous emphysema in the cheek after extraction of the maxillary third molar without using high speed hand-piece is not a common phenomenon.

In the present case, we demonstrate air emphysema in the cheek associated with hematoma after extraction of the impacted right maxillary 3rd molar. Since it was a soft tissue impaction, no hand-piece was used during the tooth removal. The purpose of this case report is to create awareness among the dental surgeons about the simple extraction procedures that may lead to air emphysema associated with hematoma.

\section{PRESENTATION OF CASE}

51-year-old medically fit, non-smoker, female patient undergoing comprehensive dental treatment with the interns at the dental hospital, Dar Al Uloom University, Saudi Arabia, exhibited swelling with bluish discoloration in the right cheek a day after extraction of the right maxillary soft tissue impacted $3^{\text {rd }}$ molar (Fig. 1). The patient gave no history of bleeding disorders, allergy or any other medical condition. After extraction, the site was debrided and sutured. On the very next day, she returned to the outpatient department with the complaints of pain and swelling with bluish discoloration in the right cheek. The patient reported that after extraction, she went home and, later on the same day, observed bluish discoloration and felt fullness in her right cheek and gradually developed dysphagia, difficulties in mastication, and limited opening of the mouth.

On extraoral examination, a bluish coloured swelling over the right buccal cheek extending from the lower margin of zygomatic arch to the inferior border of the mandible was observed (Fig.2). The swelling had also extended to the upper part of neck superoinferiorly and from ala of the nose to the tragus of the ear, mediolaterally. There was neither any sinus opening nor pus discharge at the site. No signs or symptoms of cranial nerve deficits were detected. There was no active bleeding from the site, no chest pain and dyspnoea. On palpation, tenderness in the right buccal and submandibular region and crepitus (crackling sound) were observed. The patient's vital signs were also normal. On intraoral examination, the extraction site showed typical appearance of normal healing state and, there was no tissue laceration. There was no radiographic evidence of oroantral communication. However, a complete blood count (CBC) and chest x-ray were advised to rule out any bleeding disorders and air emphysema in the chest respectively. The CBC and chest x-ray indicated no signs of bleeding disorder and air emphysema in the chest (e.g. pneumomediastinum and pneumothorax) respectively. (Fig.3)
Corresponding Author: Dr. Fatema Akhter Department of Surgical and Diagnostic Sciences, College of Dentistry, Dar Al Uloom University, Riyadh, Kingdom of Saudi Arabia. E-mail: mstfatima@dau.edu.sa

DOI: $10.14260 /$ jemds/2021/670

How to Cite This Article:

Tabassum N, Akhter F, Alfirm G, et al. Management of air emphysema with cyanosis following dental treatment: a case report with scientific reasoning. J Evolution Med Dent Sci 2021;10(37):3306-3309, DOI: 10.14260/jemds/2021/670

Submission 14-06-2021,

Peer Review 23-08-2021,

Acceptance 30-08-2021,

Published 13-09-2021.

Copyright (c) 2021 Vybhavi MK et al. This is an open access article distributed under Creative Commons Attribution License [Attribution 4.0 International (CC BY 4.0)] 


\section{CLINICAL DIAGNOSIS}

Bluish discoloration at the site of swelling was suggestive of subcutaneous bleeding from the blood vessels, indicating hematoma. On palpation, crepitus was clearly felt, further confirmed by auscultation using stethoscope a loud audible sound was heard confirming air emphysema.

\section{DIFFERENTIAL DIAGNOSIS}

It includes hematoma, air emphysema, oroantral communication, angioedema, and allergy.

\section{DISCUSSION OF MANAGEMENT}

We prescribed amoxicillin with potassium clavulanate $625 \mathrm{mg}$ twice daily for 5 days to prevent infection and ibuprofen 400 mg twice daily for 3 days. Antihistamines were also prescribed for the prophylactic management of a suspected hypersensitivity reaction. Instructions were given to avoid brisk oral rinsing, not to blow through the mouth, not to sneeze heavily, and not to smoke or use straws. On the third, fourth and seventh day, we recalled the patient and assessed the condition. Remarkable improvement was noticed on the fourth day. After one week, the patient was asymptomatic and recovered completely (Fig.4).
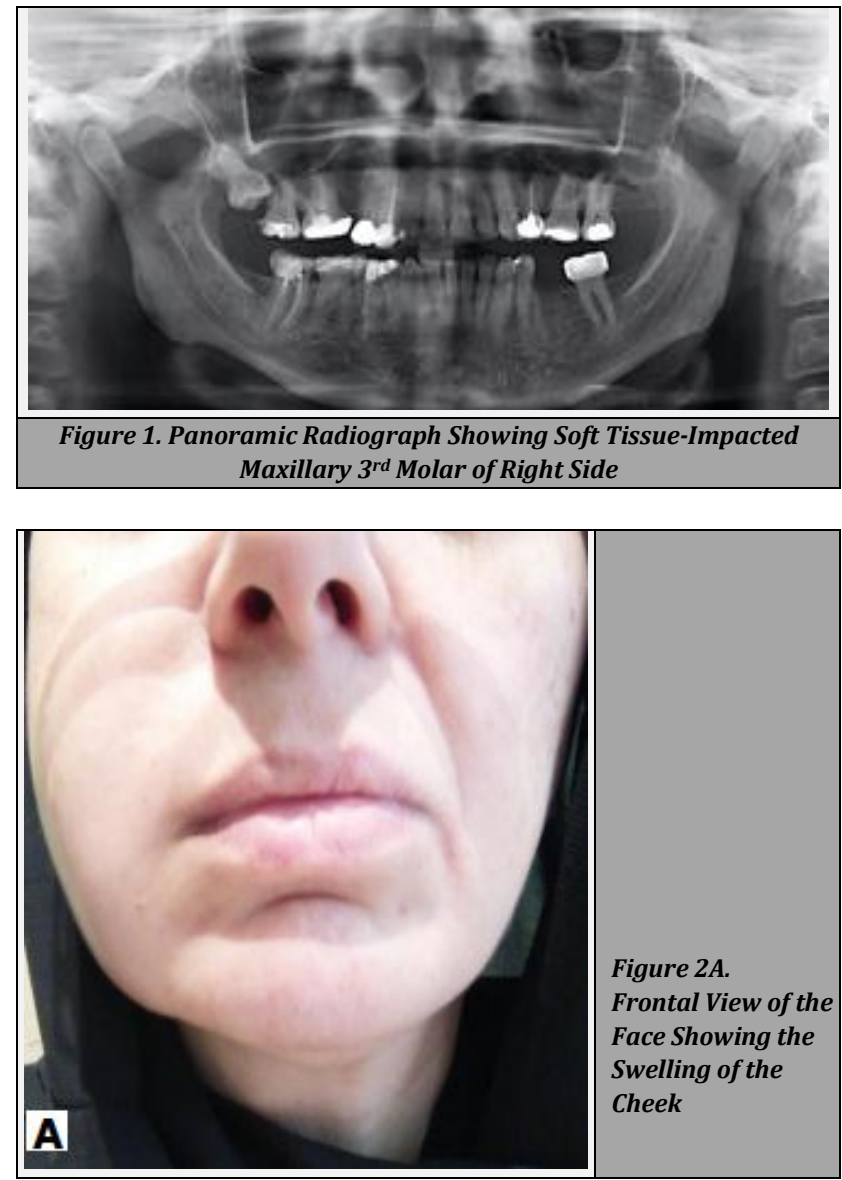


\section{DISCUSSION}

Air emphysema in fascial head and neck spaces is an escape of air from the oral cavity or through the teeth sockets or gingival or fascial spaces into the subcutaneous tissues beneath the skin, flaring or swelling of the mucosa and the overlying fascial spaces. ${ }^{11}$ If the spread is limited to the fascial spaces and oral cavity, then the condition regresses usually within 7-12 days.12-16 In early stages, the air reserves itself in the 
subcutaneous spaces until the pressure increases to push and diffuse through the adjacent area involving various head and neck fascial spaces. This can further extend into the chest region exhibiting pneumomediastinum and pneumothorax.17,18 Immediate diagnosis and use of antibiotics, analgesics, antihistamines and airway management could resolve this life-threatening entity. ${ }^{11}$

There are high chances of misdiagnosing this condition and giving a different line of treatment which may prove fatal if the diagnosis is not confirmed. ${ }^{19}$ The differential diagnosis includes hematoma, air emphysema, oroantral communication, angioedema, and allergy. This clinical presentation couldn't be due to the oroantral fistula because there were no clinical or radiographic signs and symptoms of the same. Crepitus is an important differentiating tool and is absent in angioedema, and, since the swelling was lip-sparing, angioedema was ruled out. In addition, the patient gave no history of allergy, therefore, it was less likely to be an allergic reaction. This report presented swelling with bluish discoloration suggesting subcutaneous bleeding from the blood vessels, which indicates hematoma. During palpation, the crepitus was obvious and confirmed by auscultation, which is commonly used for clinical identification of crepitus, indicating air emphysema. ${ }^{20}$

Subcutaneous air emphysema of dental origin is categorized into four types: 1) those in which intraoral pressure is increased by the activities of the patient; 2 ) those that followed by the use of compressed air with high speed hand-piece during treatment procedure; 3) those that followed complicated and lengthy extractions; 4) those with no discernible cause. ${ }^{21}$ In our present case, it seems that it falls into the 4th type.

A question may arise as to why subcutaneous air emphysema is seen in selective patients, although similar dental treatment procedures are done routinely in all the patients with varying age groups, genders, medical health, physical and mental attitude, and dental environment. One explanation to this could be the fragility of mucosa that gives way to the spread of air through the potential fascial spaces. In this report, we assumed that the escape of air with blood into the fascial spaces occurred due to the fragility of the mucosa at the extraction site resulting in hematoma and emphysema. Note that extraction was done without using high speed handpiece.

Escape of air into the neck can cause difficulty in swallowing and breathing and further extension of air into the thoracic spaces can resist the thoracic cavity during expansion, resulting in dyspnoea, and decreased $\mathrm{spo}_{2}$ causing desaturation and cardiac arrest.22,23 We did not find any clinical signs of air spreading into the neck region in the present report. In addition, we have successfully managed the case in the early stage of the symptoms, indicating that early and proper diagnosis are important factors to prevent spreading into the neighbouring spaces.

\section{CONCLUSIONS}

Initially benign and self-limiting air emphysema could turn out to be a life-threatening condition if not recognized and managed early. Therefore, it is not only the duty of the dental specialists or the physicians but also the students and interns treating these patients should be familiarized with such untoward complications and its management. It is also very important for the clinicians to recognize sudden onset of swelling and the presence of crepitus in the soft tissues during treatment procedure.

Financial or other competing interests: All Authors received grants from Dar Al Uloom University.

Disclosure forms provided by the authors are available with the full text of this article at jemds.com.

We thank the Deanship of Graduate Studies and Scientific Research at Dal Al Uloom University for the financial Support for the project.

\section{REFERENCES}

[1] Heymans, SN, Babayof I. Emphysematous complications in dentistry, 1960-1993: an illustrative case and review of the literature. Quintessence Int 1995;26(8):535-43.

[2] McKenzie W, Rosenberg M. Iatrogenic subcutaneous emphysema of dental and surgical origin: a literature review. J Oral Maxillofac Surg 2009;67(6):1265-8.

[3] Lee SW, Huh YH, Cha MS. Iatrogenic subcutaneous cervicofacial emphysema with pneumomediastinum after class V restoration. J Korean Assoc Oral Maxillofac Surg 2016;43(1):49-52.

[4] Patel N, Lazow S, Berger J. Cervicofacial subcutaneous emphysema: case report and review of literature. J Oral Maxil Surg 2010;68(8):1976-82.

[5] Hülann M, Rödig T, Nordmeyer S. Complications during root canal irrigation. Endod Top 2007;16(1):27-63.

[6] Wilson GA, Galle S, Greene C. Subcutaneous emphysema after extraction of maxillary teeth: report of a case. J Am Dent Assoc 1983;106(6):836-7.

[7] Reznick JB, Ardary WC. Cervicofacial subcutaneous air emphysema after dental extraction. J Am Dent Assoc 1990;120(4):417-9.

[8] Guest PG, Henderson S. Surgical emphysema of the mediastinum as a consequence of attempted extraction of a third molar tooth using an air turbine drill. Br Dent J 1991;171(9):283-4.

[9] Ali A, Cunliffe DR, Watt-Smith SR. Surgical emphysema and pneumomediastinum complicating dental extraction. Br Dent J 2000;188(11):589-90.

[10] Tan S, Nikolarakos D. Subcutaneous emphysema secondary to dental extraction: a case report. Aust Dent J 2017;62(1):95-7.

[11] Kukuruza K, Aboeed A. Subcutaneous emphysema. In: StatPearls. Treasure Island (FL): StatPearls Publishing 2021.

[12] Snyder MB, Rosenberg ES. Subcutaneous emphysema during periodontal surgery report of a case. J Periodontol 1977;48(12):790-1.

[13] Salib RJ, Valentine P, Akhtar S. Surgical emphysema following dental treatment. J Laryngol Otol 1999;113(8):756-8.

[14] Mayorga F, Infante P, Hernandez JM, et al. Angioneurotic edema caused by ACEI: a case report. Med Oral 2000;5(2):124-7. 
[15] Sivaloganathan K, Whear NM. Surgical emphysema during restorative dentistry. Br Dent J 1990;169(3-4):93-4.

[16] Spaulding CR. Soft tissue emphysema. J Am Dent Assoc 1979;98(4):587-8.

[17] Maunder RJ, Pierson DJ, Hudson LD. Subcutaneous and mediastinal emphysema. Pathophysiology, diagnosis and management. Arch Intern Med 1984;144(7):1447-53.

[18] Dixit R, George J. Subcutaneous emphysema in cavitary pulmonary tuberculosis without pneumothorax or pneumomediastinum. Lung India 2012;29(1):70-2.

[19] Mascarenhas RJ. Management of subcutaneous facial emphysema secondary to a class V dental restoration. Clin Case Rep 2019;7(5):1025-30.
[20] Da Costa Medeiros BJ. Subcutaneous emphysema, a different way to diagnose. Rev Assoc Med Bras (1992) 2018;64(2):159-63.

[21] Shovelton DS. Surgical emphysem as complication of dental operations. Br Dent J 1957;102(4):125-9.

[22] Abu-Omar Y, Catarino PA. Progressive subcutaneous emphysema and respiratory arrest. J R Soc Med 2002;95(2):90-1.

[23] Tran Q, Mizumoto R, Mehanna D. Management of extensive surgical emphysema with subcutaneous drain: a case report. Int J Surg Case Rep 2018;44:126-30. 